\title{
Programmed death ligand 1-associated antitumor immunity in early-stage non-small cell lung cancer: Expression of major histocompatibility complex I as a prerequisite
}

\author{
Bryan M. Burt, MD
}

From the Baylor College of Medicine, Houston, Tex.

Disclosures: Author has nothing to disclose with regard to commercial support.

Received for publication Aug 13, 2017; accepted for publication Aug 19, 2017; available ahead of print Sept 26, 2017.

Address for reprints: Bryan M. Burt, MD, Division of General Thoracic Surgery, Department of Surgery, Baylor College of Medicine, One Baylor Plaza, BCM 390, Houston, TX 77005 (E-mail: bryan.burt@bcm.edu). J Thorac Cardiovasc Surg 2018;155:393-4

$0022-5223 / \$ 36.00$

Copyright (c) 2017 by The American Association for Thoracic Surgery

http://dx.doi.org/10.1016/j.jtcvs.2017.08.061

Non-small cell lung cancer (NSCLC) has traditionally been considered a "non-immunogenic" tumor, although recent advances in immune checkpoint blockade have revolutionized the treatment of patients with advanced-stage disease. Several clinical trials have proven that patients whose tumors express high levels of programmed death ligand 1 (PDL1) ( $>50 \%$ tumor cell membranous staining by immunohistochemistry) are likely to have a clinical response to monoclonal antibodies against programmed death 1 (PD-1). ${ }^{1,2}$ This field is relatively young, however, and there are a number of opportunities for innovation and advancement. For example, only $23 \%$ to $30 \%$ of patients with advanced-stage NSCLC tumors demonstrate greater than 50\% PD-L1 staining, responses to PD-1 inhibition can be somewhat variable, and the effect of PD-1 blockage on survival is only approximately 3 to 4 months life extension. ${ }^{1-5}$ Moreover, the role of PD-1/PD-L1 blockade in early-stage NSCLC is unknown.

PD-L1 is a protein that functions to provide inhibitory signals to cytotoxic $\mathrm{T}$ cells expressing PD-1, the receptor for PD-L1, and the result is promotion of antitumor immunity. Therefore, expression of PD-L1 on NSCLC has become important in the study of lung cancer outcomes, both as a target for immunotherapy and as a biomarker for prognosis. In this issue of the Journal, Hirai and colleagues ${ }^{6}$ report a retrospective, single-institution study of 94 patients undergoing surgical resection for pathologic stage I lung adenocarcinoma to evaluate the association of PD-L1 expression on prognosis. The authors show that patients with PD-L1-positive tumors had decreased 5-year overall survival compared with patients with PD-L1-negative tumors (67\% vs $86 \%$, respectively, using a $5 \%$ PD-L1 expression cutoff, and $85 \%$ vs $40 \%$ using a $50 \%$ PD-L1 cutoff).

Correlation of higher tumor cell PD-L1 expression with decreased overall and recurrence-free survival in NSCLC has been documented in a number of studies, all of which were well referenced by Hirai and colleagues. ${ }^{6}$ The authors also cite a number of studies in which PD-L1 did not correlate with survival outcomes in NSCLC, as well as the few

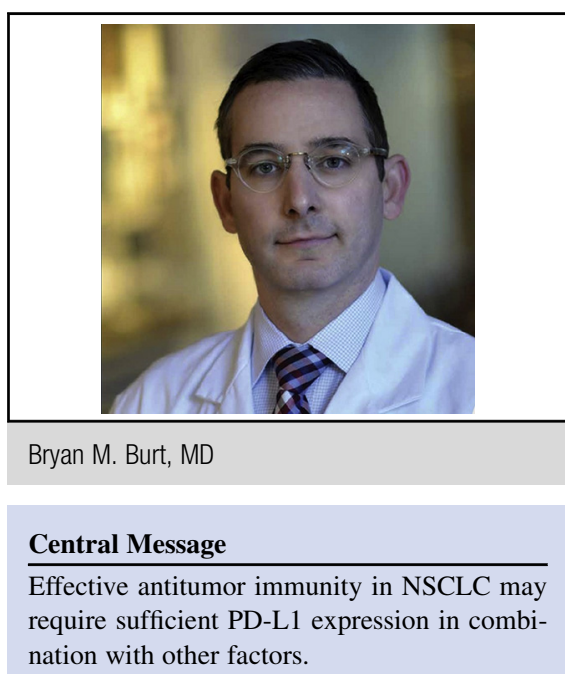

See Article page 382 .

studies in which high PD-L1 expression was associated with improved survival in NSCLC. Such variability may be accounted for, to some degree, by the novel finding presented by the authors in their study regarding NSCLC tumor cell expression of HLA class I, a protein important for presentation of antigens to cytotoxic $\mathrm{T}$ cells. The authors demonstrated that positive expression of PD-L1 on tumor cells was associated with unfavorable overall survival in early-stage lung adenocarcinoma only when human leukocyte antigen (HLA) class I was concurrently expressed on tumor cells at normal levels and that PD-L1 expression was not associated with survival when HLA class I expression was reduced. This suggests that NSCLC tumors with decreased HLA class I may evade immune surveillance regardless of PD-L1 expression and that NSCLC tumor cells with normal HLA class I may evade immune surveillance only when they express PD-L1.

Taken together, the prognostic and therapeutic implications of PD-L1 expression on NSCLC are most certainly influenced by other factors required for antitumor immunity. Although the data on HLA class I expression presented in this article must be considered exploratory given the relatively small sample size from which they were derived, such data have important implications for PD-L1 as a biomarker for prognosis and for response to immunotherapy in lung cancer, and deserve careful further study. Currently enrolling is a phase II, multicenter clinical trial of 
neoadjuvant and adjuvant PD-L1 blockade for patients with operable stage Ib-IIIa NSCLC (NCT02927301), which may afford us some of these opportunities. From this trial, we can expect to understand how pathologic and clinical treatment responses are related to the degree of PD-L1 expression in a cohort of operable patients with NSCLC, and the translational science infrastructure of this trial may facilitate investigation of other factors that influence antitumor immune responses, including the importance of HLA expression.

\section{References}

1. Garon EB, Rizvi NA, Hui R, Leighl N, Balmanoukian AS, Eder JP, et al. Pembrolizumab for the treatment of non-small-cell lung cancer. N Engl J Med. 2015;372: 2018-28.
2. Reck M, Rodriguez-Abreu D, Robinson AG, Hui R, Csoszi T, Fulop A, et al. Pembrolizumab versus chemotherapy for PD-L1-positive non-small-cell lung cancer. N Engl J Med. 2016;375:1823-33.

3. Herbst RS, Baas P, Kim DW, Felip E, Perez-Gracia JL, Han JY, et al. Pembrolizumab versus docetaxel for previously treated, PD-L1-positive, advanced non-smallcell lung cancer (KEYNOTE-010): a randomised controlled trial. Lancet. 2016; 387:1540-50.

4. Brahmer J, Reckamp KL, Baas P, Crino L, Eberhardt WE, Poddubskaya E, et al. Nivolumab versus docetaxel in advanced squamous-cell non-small-cell lung cancer. N Engl J Med. 2015;373:123-35.

5. Borghaei H, Paz-Ares L, Horn L, Spigel DR, Steins M, Ready NE, et al. Nivolumab versus docetaxel in advanced nonsquamous non-small-cell lung cancer. $N$ Engl J Med. 2015;373:1627-39.

6. Hirai A, Yoneda K, Shimajiri S, Kuroda K, Hanagiri T, Fujino Y, et al. Prognotic impact of PD-L1 expression in correlation with HLA class I expression in stage I adenocarcinoma of the lung. J Thorac Cardiovasc Surg. 2018;155: 382-92. 